\title{
Functional Assesment of Patients With AIDS Disease
}

\author{
Marise Bueno Zonta, Sérgio Monteiro de Almeida, \\ Mirian T. M. de Carvalho and Lineu César Werneck
}

\author{
Clinical Hospital of Federal University of Paraná, \\ Neurology Section, Infectious Diseases Section, \\ Curitiba, PR, Brazil
}

\begin{abstract}
We documented the types and degree of functional disability in 74 patients with AIDS at the Hospital de Clínicas of the Federal University of Paraná, Brazil. Few of these patients are referred for rehabilitation services and there is only a limited team approach in their care. We found that $91 \%$ of the patients had some degree of functional impairment; in $81 \%$ the complaint was weakness and in $\mathbf{4 7 \%}$ it was neurological involvement. According to the Barthel Index, $79 \%$ were considered functionally independent, $14 \%$ partially dependent and $7 \%$ dependent. For most of them, independence requires effort and their quality of life is reduced. Severe disability was rather unusual, while mild or moderate disability levels were not. The functional physical disability found in $21 \%$ of the patients required management by a rehabilitation team. We conclude that it is important to focus attention on the quality of life of patients with AIDS.

Key Words: HIV, AIDS, rehabilitation, functional disability, health status, neurological manifestation.
\end{abstract}

Latin America is the third most affected region of the Acquired Immunodeficiency Syndrome (AIDS) epidemic and Brazil is the country with the largest number of infected people. Nearly 600,000 individuals are infected in Brazil with the immunodeficiency virus (HIV), most or all of who will eventually develop AIDS. This disease is over all the country; 1,552 of the 5,559 counties reported at least one case in the period of 1999 to 2000; most of these places have a population lower than or around 50 thousand inhabitants [1].

HIV infection has a propensity, through direct invasion or through secondary infections and neoplasms, to involve multiple organ systems, producing an astonishing variety of disabling conditions [2,3]. HIV infection, with current treatment, is now considered a chronic condition, with patients experiencing an increase in life expectancy [2,4-7]. This prolonged survival associated with physical

Received on 10 January 2003; revised 14 September 2003.

Address for correspondence: Dr. Marise B. Zonta. Hospital das Clínicas (UFRJ), Setor de Neurologia. Rua General Carneiro, 181, sala 1238, Zip code: 80060-800, Curitiba/PR, Brazil. Phone/ Fax:(55 41) 264-3606.E-mail: marise.zonta@terra.com.br

The Brazilian Journal of Infectious Diseases 2003;7(5):301-306 (C) 2003 by The Brazilian Journal of Infectious Diseases and Contexto Publishing. All rights reserved. disability can compromise the functional independence of patients, their capacity for self-care and mobility, and their capacity for work and productivity. The economic as well as the social impact of the HIV epidemic is and will probably continue to be significant, both for the patient himself and his family, as well as for the health care system. The clinical management of AIDS has centered on control and prevention of further HIV infection and treatment strategies for those already infected, both symptomatic and asymptomatic [4]. The treatment of life-threatening complications in HIV disease has received more attention than the treatment of future sequelae. But, as the number of persons with symptomatic HIV infection increases, more attention to the management of the functional disability will be necessary to provide a better quality of life. Little research exists in Brazil on the variety and prevalence of disability in the Aids population [5]. The purpose of this study was to evaluate, document and describe the patterns of functional disabilities in a large population of AIDS patients.

\section{Materials and Methods}

Patients. We studied 74 inpatients admitted to the Universidade Federal do Paraná, Brazil, in Curitiba, at 
the Infectology, Medical and Neurology Clinics. All evaluations were performed by one of the authors (ZMB) in the period between May/2000 and January/ 2001, and each patient was seen once. All patients had proven HIV infection, and all met the Center for Disease Control criteria for the diagnosis of AIDS [8]. The patient's physical capacity was classified by the Karnofsky Scale [9]. All the patients invited to participate in this study consented to do so and signed a written consent.

Evaluation procedure. It consisted of an interview with the patient, administration of standard functional assessment instruments, a specific physical exam and retrospective examination in the hospital records. In the interview the patients were questioned about the presence of any kind of motor disability, when it started and what other factors they could relate to it. They were asked to describe the amount of difficulty that they felt in their daily activities. We measured the functional independence using the Functional Independence Measure Scale (FIM) [10] (With permission of the Research Committee of Uniform Data System for Medical Rehabilitation), the Barthel Index [11] and the Rankin score [12]. The evaluation was completed by actual patient observation or simulation of functional activity. Consultation with the patients' primary nurse or caregivers was also utilized and was especially helpful in completing the social cognition assessment. The physical exam consisted of measuring the muscular strength of muscular groups or of specific muscles (upper limbs: deltoid, biceps, triceps and palmar flexors; lower limbs: hip flexors, quadriceps, hamstrings, dorsal flexors). Strength was classified from 0 (absent muscular contraction) and 5 (normal active movement) [13].

\section{Results}

Demographic characteristics. The study population consisted of 46 men (62\%) and 28 women (38\%). Sixty-seven patients $(91 \%)$ were white, $4(5 \%)$ were black and $3(4 \%)$ were dark. The mean age was 35 (range 20 to 55). The mean number of study years was $6 \pm 3(n=48$, range $0-15)$. Nineteen (20\%) of them had no personal records about the primary risk factor for HIV infection. In the other 55, transmission was due mainly to sexual contact $(45 \%)$ and to the use of intravenous drugs (46\%).

Clinical data about infection. Among the 74 patients evaluated, 44 had an AIDS-defining illness during hospitalization for a total of $51 \%$. According to the Karnofsky's scale $(n=74)$, the average was $80 \%$ with a standard deviation of $19 \%$. Other data on clinical and immune assessment can be found in Tables 1 and 2 .

Among the 74 patients, 67 (91\%) reported impaired physical activity; a complaint about various degrees of weakness was made by 60 patients $(81 \%)$. Among those 7 patients with no complaint of weakness, motion difficulty was due to lower limb pain and edema, as well as balance and visual impairments. When questioned about the type of weakness 36 patients (49\%) indicated that they maintained all of their activities, although at a slower pace, with stops for rest; 18 patients $(24 \%)$ realized they had difficulty and needed more effort, 6 patients $(8 \%)$ felt like staying in bed and 14 patients (19\%) had no complaint of weakness. Among the 74 patients, 12 (16\%) did not have any professional activity previous to the disease diagnosis. Twenty-two of them (30\%) continued with their professional activities, 36 (49\%) left their professions for reasons related to the infection and 4 (5\%) left their professions for other reasons. The most common complaints about disabling neurological involvement were: paresthesia in 22 patients (30\%), balance impairment in $12(16 \%)$, hemiparesis in 8 $(11 \%)$, headache in $6(8 \%)$ and other types of pain in $11(15 \%)$, convulsion in $6(8 \%)$, disorientation in $5(7 \%)$, among others such as diplopia (4\%), memory lapses (3\%) and paraparesis (1\%).

In terms of disability, we found the following, according to the scales:

1. FIM scores $(n=36)$. Twenty-four patients $(67 \%)$ of the 36 tested had scores over 6 , without any further need for help. Among these, 16 patients were independent, 3 presented some difficulty in only one 
Table 1. Clinical and immunological characteristics of the assessment of AIDS patients

\begin{tabular}{lccc}
\hline & Mean & SD & N \\
\hline Duration of HIV diagnosis (months) & 35 & 40 & 74 \\
Duration of AIDS diagnosis (months) & 8 & 15 & 74 \\
Viral Load** & 161,516 & 422,386 & 23 \\
$\mathrm{CD}_{4}$ & 94,1 & 119 & 72 \\
$\mathrm{CD}_{8}$ & 642 & 589 & 68 \\
$\mathrm{CD}_{4} / \mathrm{CD}_{8}$ & 0.24 & 0.39 & 68 \\
\hline
\end{tabular}

* Standard Deviation

** Viral Load during the previous three months

Table 2. Characteristics of motor assessment of AIDS patients

\begin{tabular}{lllrrr}
\hline & \multicolumn{2}{c}{ Yes } & & \multicolumn{2}{c}{ No } \\
\cline { 2 - 5 } & N & \% & & N & \% \\
\hline Complaint of weakness & 60 & 81 & 14 & 19 \\
Complaint of impairment & 67 & 91 & 7 & 9 \\
Alteration in muscle strength & 35 & 47 & 39 & 53 \\
Neurological involvement & 35 & 47 & 39 & 53 \\
\hline
\end{tabular}

Table 3. Functional assessment in AIDS patients

\begin{tabular}{|c|c|c|c|c|c|c|}
\hline & \multicolumn{2}{|c|}{ Barthel } & \multicolumn{2}{|c|}{ FIM } & \multicolumn{2}{|c|}{ Rankin } \\
\hline & $\mathbf{N}$ & $\%$ & $\mathbf{N}$ & $\%$ & $\mathbf{N}$ & $\%$ \\
\hline Dependent & 5 & 7 & 6 & 17 & 4 & 5 \\
\hline Partially dependent & 10 & 14 & 6 & 17 & 8 & 11 \\
\hline Independent & 59 & 79 & 24 & 56 & 62 & 84 \\
\hline Total & \multicolumn{2}{|c|}{74} & \multicolumn{2}{|c|}{36} & \multicolumn{2}{|c|}{74} \\
\hline
\end{tabular}

The FIM $^{\mathrm{MT}}$ instrument. Copyright $\odot 1997$ Uniform Data System for Medical Rehabilitation (UDSMR). All rights reserved. Used with permission of UDSMR, University at Buffalo, 232 Parker Hall, 3435 Main Street, Buffalo, NY 14214. 
item with the need of handrail support to climb stairs and 5 needed some type of support for 3 or more areas. The other 12 patients (33\%) required human assistance (FIM score of 5 or less), 6 of them needed human help for less than 4 items, and 6 required human assistance for 10 or more items. The items most often requiring human assistance were stair climbing (31\%), ambulation $(25 \%)$ and bathing $(25 \%)$. Activities in which patients showed complete independence most often (FIM score $=7$ ) were bladder management $(86 \%)$, and communication and social cognition (all items at $86 \%$ ) (Table 3 ).

2. Barthel index ( $n=74)$. Fifty-nine patients $(79 \%)$ of the 74 tested obtained a score equal to or higher than 85 , being considered independent in their daily life activities. Ten patients $(14 \%)$ had a score between 50 and 80 , being considered partially dependent. Five patients $(7 \%)$ had a score below 45 , thus being considered dependent. The items most often requiring assistance were stair climbing (27\%), mobility (26\%) and transfers (24\%). The items for which patients were most often completely independent were grooming (93\%), feeding (88\%), and bladder control (88\%) (Table 3).

\section{Rankin score $(n=74)$. Twenty-eight patients (38\%)} of the 74 tested had score I, being considered independent and able to continue previous routine activities. Thirty-four patients (46\%) had score II, being considered independent for ADLs but still unable to return to their previous activities. Six patients $(8 \%)$ had score III, being considered moderately dependent, and requiring minimum assistance. Two patients $(3 \%)$ were considered very dependent and 4 patients $(5 \%)$ were totally dependent, both groups requiring 24-hour supervision (Table 3).

\section{Discussion}

Most referrals of AIDS patients to rehabilitation services are because of pulmonary complications or acute illness. Presently, some patients are receiving orientation about physical activity but only a few were directed towards professional help, especially at the onset of the illness. HIV infection has a propensity to produce a great variety of disabling conditions, and functional disability is generally the patient's primary problem [14]. Our data confirm this in the great majority of patients $(91 \%)$ presenting some degree of functional disability. The most common manifestation leading to disability was weakness, a complaint made by $81 \%$ of the patients, a factor that prevents them from continuing vocational activities, hobbies, and self-care; this was also observed by Levinson [2]. Although 79\% were considered independent for the activities of daily living, approximately $46 \%$ were not able to return to their previous activities and $49 \%$ had already left their professional lives because of the HIV infection (disease-related factors). In a study made of 391 persons with AIDS, disability was relatively unusual, mild and moderate disability were more common, data also confirmed by our study [14].

The scales used in this study were able to assess the existence of weakness and quantify its affect on daily living activities. The FIM scale provides more details on the amount of help required; its reliability is 0.95 [15 - 19]. In cases with a higher weakness level the scales pointed towards stair climbing and ambulation as the physical activities demanding greatest effort among the items assessed. On the other hand the scales do not assess the quality of activity accomplishment in the sense of determining the degree of difficulty of those individuals who need neither human help nor assisting devices. In our case that would mean, basically, the ability to determine the weakness rate in the persons with HIV disease. Neurological complications are very common, debilitating and life-threatening in persons with HIV disease [20-24]. In our study we observed that 22 patients (30\%) had a complaint about paresthesia, 12 patients $(16 \%)$ had balance impairments and 8 patients $(11 \%)$ had hemiparesis. The presence of these forms of impairment areindications that rehabilitation professionals should become involved in the care of persons with HIV. The management of functional deficits in AIDS is no different from that used in corresponding non-HIV processes. Considering that disability is present in most of this population and that this is one of the most 
important determinants of the quality of life, more attention should be given to preventive measures. Whenever possible, weakness should be prevented through careful attention to nutrition, a light resistive exercise program, and the encouragement of physical activity. Suggestions from various studies point to the need to encourage the $\mathrm{HIV}^{+}$patient to begin an exercise program, preferably while they are at early stages of the disease. Physical activity can have a significant impact on several important components of good health. Some of the benefits noted are improved aerobic capacity and functional status, improved immune function/indices, maintenance of or improvement in lean body mass/ weight, improved mood (reduced depressive symptoms), and improvement in the quality of the patients' lives. For individuals with AIDS the recommendation is for moderate aerobic exercise [25-29]. Rehabilitation professionals will increasingly play a central role in enhancing the quality of life of these individuals [30-33]. They must become familiar with the clinical behavior and prognosis of those aspects of AIDS that commonly lead to disability. In Brazil, the teamwork concerning this subject-matter is still unfortunately far from ideal. The patients' access to rehabilitation services depends not only on government initiatives and health plans but on the medical community as well, including the qualification of rehabilitation professionals for appropriate treatment. More effort should be made to encourage a team approach, which is essential to provide better treatment opportunities for this new group of patients.

\section{Refernces}

1. Ministério da Saúde, Boletim Informativo - AIDS - 2000, Brasil.

2. Levinson S.F., O'Connell P.G. Rehabilitation Dimensions of Aids: A review. Arch Phys Med Rehabil 1991;72:690-6.

3. Veronesi R., Focaccia R., Mazza C.C., Weinberg A. AIDS/ SIDA Síndrome de Imunodeficiência Adquirida. In: Neuroinfecção. Machado L.R., Nóbrega J.P.S., Livramento J.A., Spina A. São Paulo: USP; 1994. p.25568.

4. O’Dell M.W., Crawford A., Bohi E.S., Bonner F.J. Disability in persons hospitalized with AIDS. Am J Phys Med Rehabil 1991;70:91-5.
5. Rosensweet E., Fink C.J. Physical Therapy for the patient with Acquired Immunodeficiency Syndrome. Clin Podiat Med Surg 1992;9:883-93.

6. O’Connell P.G., Levinson S.F. Experience with rehabilitation in the Acquired Immunodeficiency Syndrome. Am J Phys Med Rehabil 1991;70:195-200.

7. MacDougall D.S. Pediatric HJV: Evaluation, management, and rehabilitation. J Int Assoc Phys AIDS Care 1998;May:16-25.

8. Centers for Disease Control. 1993 revised classification system for HIV infection and expanded surveillance case definition for AIDS among adolescents and adults. MMWR 1992;41:1-19.

9. Karnofsky D.A., Abelmann W.H., Craver L.V., Burchenal J.H. The use of the nitrogen mustards in the palliative treatment of carcinoma : With particular reference to broncogenic carcinoma. Cancer 1948; 1 :634-56.

10. Granger C., Hamilton B. Development of a Uniform National Data System For Medical Rehabilitation 198497. Final Report for Grant Number G008435062. Buffalo: National Institut on Disability and Rehabilitation Research, Office of Special Education and Rehabilitative Services, Department of Education, 1987.

11. Mahoney F.I., Barthel D.W. Functional Evaluation: The Barthel Index. Md St Med J Baltimore 1965;14:61-5.

12. Rankin J. Cerebral vascular accidents in patients over the age of 60.2: Prognosis. Scott Med J 1957; 2:200.

13. Dejong R.N. The Neurologic Examination. 3. ed. New York: Harper and Row Publishers; 1967.

14. O'Dell M.W. HIV-related neurological disability and prospects for rehabilitation. Disabil Rehabil 1996; $18: 285-92$.

15. Heinemann A.W., Linacre J.M., Wright B.D., et al. Prediction of rehabilitation outcomes with disability measures. Arch Phys Med Rehabil 1994;75:133-43.

16. Hall K.M.,Johnston M.V. Measurement tools for a nationwide data system. Arch Phys Med Rehabil 1994; $75: 10-8$

17. Linacre J.M., Heinemann A.W., Wright B.D., et al. The structure and stability of the Functional Independence Measure. Arch Phys Med Rehabil 1994;75:127-32.

18. Hobart JC,.Lamping D.L., Freeman J.A., et al. Evidence-based measurement: Which disability scale for neurologic rehabilitation? Neurology 2001; 57:639-44.

19. Ottenbacher K.J., Hsu Y., Granger C.V., Fiedler R.C. The reliability of the functional independence measure: A quantitative review. Arch Phys Med Rehab 1996; 77:1226-32.

20. Shifitto G., Kieburtz K., McDermott M.P., et al. Clinical trials in HIV-associated cognitive impairment: Cognitive and Functional outcomes. Neurology 2001;56:415-8. 
21. Bruck I., Tahan T.T., Cruz C.R., et al. Developmental milestones of vertically HIV infected and seroreverters children : Follow up of 83 children. Arq Neuropsiquiatr 2001;59:691-5.

22. Berger J.R., Simpson D.M. Neurologic Complications of AIDS. In: Infections of the Central Nervous System. Scheld WM, Whitley RJ, Durack DT. 2 ed Philadelphia: Lippincott-Raven Publishers; 1997:p.255-67.

23. Mocsny N., MED R.N. Toxoplasmic encephalitis in the AIDS patient. Rehabil Nurs 1993;18: 20-5.

24. Rosen L., Strax T.E., Bakst B. HIV and the nervous system: Implications for rehabilitation (abstract). Arch Phys Med Rehabil 1988;69:716.

25. Birk T.J. How much exercise is appropriate for the patient with HIV? Sports Med Prim Care 1998; June:50-2.

26. Spense D.W., Galantino M.L.A., Mossberg K.A., Zimmerman S.O. Progressive resistence exercise: Effect on muscle function and anthropometry of a select AIDS population. Arch Phys Med Rehabil 1990;71:644-8.

27. Pedersen B.K., Nieman D.C. Exercise immunology: Integration and regulation. Immunology Today 1998; 19:204-6.

28. Stringer W.W. HIV and aerobic exercise. Current recommendations. Sports Med 1999; 28:389-95.

29. LaPerriere A., Klimas N., Fletcher M.A., et al. Change in $\mathrm{CD}_{4}^{+}$cell enumeration following mechanisms and practical applications. Int J Sports Med 1997; 18:S56S61.

30. Pizzi M. Occupational therapy: Creating possibilities for adults with HIV infection, ARC and AIDS. AIDS Patient Care 1989; Feb:18-23.

31. Gutterman L. A Day Treatment for persons with AIDS. Am J Occup Ther 1990;44:234-7.

32. Merritt L., Hirsch D.D., Smith C. Inpatient rehabilitation of acquired immunodeficiency syndrome (abstract). Arch Phys Med Rehabil 1988;69:716.

33. Furth P.A., Maloof M., Flynn J.P.G. Rehabilitation and AIDS - primary care or system support (abstract). Arch Phys Med Rehabil 1987;68:661. 